\title{
MET NP_000236.2:p.Y1230H
}

National Cancer Institute

\section{Source}

National Cancer Institute. MET NP 000236.2:p.Y1230H. NCI Thesaurus. Code C162280.

A change in the amino acid residue at position 1230 in the hepatocyte growth factor receptor protein where tyrosine has been replaced by histdine. 